International Conference on Advanced Research in MANAGEMENT, ECONOMICS AND ACCOUNTING

\title{
The Dynamics of India's Major Exchange Rates
}

\author{
${ }^{1}$ Ranajoy Bhattacharyya, ${ }^{2}$ Radhika Prosad Datta
}

${ }_{1,2}$ Indian Institute of Foreign Trade

\begin{abstract}
In this paper we analyse the dynamic properties of India's major exchange rates both in the short and the long run. The particular issue of our concern is to find whether present values of the exchange rates depend (a) on their own past values and (b) on the past values of India's other exchange rates. Since the series exhibit long memory, the ARFIMA model is used for the first purpose and the entropy transfer and vector auto regression models are used for the later purpose. Combining the results of these models we conclude that in general the Indian exchange rates are persistent and depend only on their immediate past values. In particular, past values older than two periods (days in this case) do not appear to be consistently relevant in modelling the current value. These observations have clear implications for exchange rate trades using technical analysis and for exporters and importers.
\end{abstract}

Keywords: India's exchange rates, ARFIMA, Vector Auto Regression, Information Transfer, Technical analysis. 